\title{
Roles of Melatonin in Goat Hair Follicle Stem Cell Proliferation and Pluripotency Through Regulating the Wnt Signaling Pathway
}

\author{
Weidong Zhang ${ }^{1}$, Niu Wang ${ }^{1}$, Tongtong Zhang ${ }^{1}$, Meng Wang ${ }^{1}$, Wei Ge ${ }^{2}$ and Xin Wang ${ }^{1 *}$ \\ ${ }^{1}$ College of Animal Science and Technology, Northwest A\&F University, Yangling, China, ${ }^{2}$ College of Life Sciences, Qingdao \\ Agricultural University, Qingdao, China
}

OPEN ACCESS

Edited by:

Zi-Bing Jin,

Capital Medical University, China

Reviewed by:

Ronghuan Yin,

Shenyang Agricultural University,

China

Antonio Giordano,

Temple University, United States

${ }^{*}$ Correspondence:

Xin Wang

xinwang5@nwsuaf.edu.cn

Specialty section:

This article was submitted to

Stem Cell Research,

a section of the journal

Frontiers in Cell and Developmental

Biology

Received: 28 March 2021

Accepted: 03 May 2021

Published: 04 June 2021

Citation:

Zhang W, Wang N, Zhang T, Wang M, Ge W and Wang X (2021)

Roles of Melatonin in Goat Hair

Follicle Stem Cell Proliferation and Pluripotency Through Regulating

the Wnt Signaling Pathway.

Front. Cell Dev. Biol. 9:686805.

doi: 10.3389/fcell.2021.686805
Emerging studies show that melatonin promotes cashmere development through hypodermic implantation. However, the impact and underlying mechanisms are currently unknown. In vitro study has previously demonstrated that melatonin induces cashmere growth by regulating the proliferation of goat secondary hair follicle stem cells (gsHFSCs), but there is limited information concerning the effects of melatonin on cell pluripotency. It is also known that Wnt signaling may actively participate in regulating cell proliferation and stem cell pluripotency. Therefore, in the current investigation, goat hair follicle stem cells were exposed to multiple concentrations of melatonin and different culture times to reveal the relationship between melatonin and the activation of Wnt signaling. A proportionally high Catenin beta-1 (CTNNB1) response was induced by $500 \mathrm{ng} / \mathrm{L}$ of melatonin, but it was then suppressed with the dosages over 1,000 ng/L. Greater amounts of CTNNB1 entered the cell nuclei by extending the exposure time to $72 \mathrm{~h}$, which activated transcription factor 4/lymphoid enhancer-binding factor 1 and promoted the expression of the proliferation-related genes C-MYC, C-JUN, and CYCLIND1. Moreover, nuclear receptor ROR-alpha $(\mathrm{ROR} \alpha)$ and bone morphogenetic protein 4 (BMP4) were employed to analyze the underlying mechanism. $R O R \alpha$ presented a sluggish concentration/time-dependent rise, but BMP4 was increased dramatically by melatonin exposure, which revealed that melatonin might participate in regulating the pluripotency of hair follicle stem cells. Interestingly, NOGGIN, which is a BMP antagonist and highly relevant to cell stemness, was also stimulated by melatonin. These findings demonstrated that melatonin exposure and/or NOGGIN overexpression in hair follicle stem cells might promote the expression of pluripotency markers Homeobox protein NANOG, Organic cation/carnitine transporter 4, and Hematopoietic progenitor cell antigen CD34. Our findings here provided a comprehensive view of Wnt signaling in melatonin stimulated cells and melatonin mediated stemness of gsHFSCs by regulating NOGGIN, which demonstrates a regulatory mechanism of melatonin enhancement on the growth of cashmere.

Keywords: melatonin, cashmere, hair follicle stem cells, Wnt pathway, CTNNB1

\footnotetext{
Abbreviations: CTNNB1, Catenin beta-1; TCF4, Transcription factor 4; LEF1, Lymphoid enhancer-binding factor 1; ROR $\alpha$, nuclear receptor ROR-alpha; BMP4, Bone morphogenetic protein 4; NANOG, Homeobox protein NANOG; OCT4, Organic cation/carnitine transporter 4; CD34, Hematopoietic progenitor cell antigen CD34.
} 


\section{INTRODUCTION}

Melatonin ( $N$-acetyl-5-methoxytryptamine), a conserved pineal gland secretory product, which has been documented for more than 60 years is known to regulate many physiological events, such as circadian rhythmicity, seasonal adaptation, and reproductive changes (Johnston and Skene, 2015; Slominski et al., 2018). In domestic animals, the secretion of melatonin is regulated by natural daylight showing a circadian rhythm and higher serum concentration in seasons with a shorter day length (Nozaki et al., 1990; Buchanan et al., 1992; Alila-Johansson et al., 2001).

Cashmere is a type of amyelinic fiber produced from secondary hair follicles (SHFs) in Cashmere goats. The growth of cashmere is photoperiod-dependent, and shows seasonal changes in many goat breeds (Zhang et al., 2019b). Each year, cashmere starts growing in late-summer, halts growth in mid-winter, and naturally sheds in spring. These cyclical changes shift through three periods of cell activity: anagen, catagen, and telogen (Zhang et al., 2014). Similar periodic processes of correlation have been noted between hair follicle growth and serum melatonin levels. Higher levels of melatonin are secreted in early anagen, which suggests that melatonin probably influences the cashmere growth process (Emesih et al., 1993; Chong et al., 2019; Zhang et al., 2019a). Of particular interest, melatonin exhibits characteristic biological functions in regulating goat hair growth (Fu et al., 2014; Li et al., 2019; Yang et al., 2019b). Following subcutaneous melatonin implantation, hair follicle development in newborn goats is significantly increased (Yang et al., 2019a). Melatonin boosts cashmere production by altering the hair growth cycle and structure (O’Neill et al., 1992; Duan et al., 2015; Ge et al., 2018; Feng and Gun, 2021). It has also been shown that, in vitro, melatonin enhances the elongation of cashmere hair shafts by promoting the proliferation of hair follicle stem cells (Ge et al., 2018). However, there is limited information concerning the mechanism of melatonin action on hair growth.

The Wnt pathway is essential to the initiation of hair growth (Andl et al., 2002; Zhang et al., 2009; Feng and Gun, 2021), and transmits signals among many types of stem cells during the formation of hair placodes (Zhang et al., 2009). Catenin beta-1 (CTNNB1), a downstream signal molecule in the Wnt pathway, is an essential factor in deciding hair follicle stem cell fate and mediating the formation of follicular keratinocytes (Huelsken et al., 2001). Following a Wnt signal, CTNNB1 translocates to the nucleus, triggers the CTNNB1/TCF enhancer factor transcriptional machinery, and finally upregulates downstream factors (Ishitani et al., 2003). Transcription factor 4 (TCF4) always works as an intranuclear member of CTNNB1/TCF enhancer factors which activate or inhibit the transcription of target genes (Omer et al., 1999). It has been reported that TCF4 regulates the proliferation and secretory activity of dermal papilla cells by regulating downstream gene expression (Xiong et al., 2014). Complex assemblies of CTNNB1/lymphoid enhancerbinding factor 1 (LEF1) also activate target transcription genes and act as promoters of hair follicle stem cell cornification (Driskell et al., 2007). Insufficient LEF1 leads to a reduction of body hair and the loss of whiskers (Van Genderen et al.,
1994). Our previous study found that CTNNB1 was differentially expressed in melatonin exposed goat secondary hair follicle stem cells (gsHFSCs) compared with the control group, which revealed that melatonin is involved in regulating the state of gsHFSCs through the Wnt pathway (Ge et al., 2018). However, the regulatory mechanism of melatonin needed to be described more clearly.

In the current study, gsHFSCs were exposed to different concentrations and time periods of melatonin, and an optimum melatonin exposure concentration and time were determined by comparing the expression of CTNNB1 in the cells. Subsequently, TCF4 and LEF1 - the downstream factors of C-MYC, C-JUN, and G1/S-specific cyclin-D1 (CYCLIND1)-were detected to further determine the roles of melatonin in the Wnt activation of gsHFSCs. Moreover, the cell growth and differentiation related factors of bone morphogenetic protein 4 (BMP4)/NOGGIN and the stemness related factor homeobox protein NANOG (NANOG), organic cation/carnitine transporter 4 (OCT4), and hematopoietic progenitor cell antigen CD34 (CD34) were also detected in gsHFSCs after melatonin stimulation. These findings broaden our understanding of the mechanisms involved in melatonin-dependent goat cashmere growth.

\section{MATERIALS AND METHODS}

\section{Isolation and Cultivation of gsHFSCs}

The method for isolating gsHFSCs was similar to that previously reported (Ge et al., 2018). Briefly, goat secondary hair follicles were separated with ophthalmic forceps from newly collected fresh goat skin samples of body side, then the hair bulb regions of the separated follicles were dissected and trypsinized using $0.25 \%$ trypsin-EDTA solutions. The gsHFSCs were cultured in adherent culture dishes with DMEM/F12 media containing penicillin $(100 \mathrm{U} / \mathrm{mL})$, streptomycin $(100 \mathrm{mg} / \mathrm{mL}), 20 \mathrm{ng} / \mathrm{mL}$ epidermal growth factor, and $40 \mathrm{ng} / \mathrm{mL}$ recombinant human FGF-basic. After authentication of cells using the hair follicle stem cell markers ITGB1, CD34, K15, and non-hair follicle marker K10, different dosages of melatonin were added to cell culture media to explore the optimum concentration $(125,250$, $500,1,000,2,000$, and 5,000 $\mathrm{ng} / \mathrm{L})$ and exposure time $(12,24,36$, $48,60,72$, and $84 \mathrm{~h})$.

\section{Immunofluorescence Analysis}

Cells grown on coverslips were fixed with $4 \%$ paraformaldehyde for $15 \mathrm{~min}$. They were then permeabilized in $0.5 \%$ Triton X-100 PBS solution for $15 \mathrm{~min}$, and incubated in block solution (PBS with $0.5 \%$ triton $\mathrm{X}-100$ and $10 \%$ goat serum) for $>30 \mathrm{~min}$ at room temperature (RT). After blocking, the cells were incubated overnight at $4^{\circ} \mathrm{C}$ with primary antibodies against CTNNB1, LEF1, TCF4, C-MYC, C-JUN, CYCLIND1, CDK6, nuclear receptor ROR-alpha (ROR $\alpha)$, BMP4, NOGGIN, NANOG, OCT4, and CD34 (shown in Table 1). Then, after rewarming to RT, the IgCY3/FITC-conjugated secondary antibodies (Abcam, ab150078 or ab150073) were incubated for $1 \mathrm{~h}$, and Hoechst 33342 was used to stain the nuclei. Finally, slides were examined 
TABLE 1 | Information of primers for real-time quantitative PCR.

\begin{tabular}{|c|c|c|c|c|c|}
\hline \multirow[t]{2}{*}{ Gene symbol } & \multirow[t]{2}{*}{ Whole gene name } & GenBank & \multirow[t]{2}{*}{ Primer sequence $\left(5^{\prime}-3^{\prime}\right)$} & \multirow[t]{2}{*}{ Prodution size (bp) } & \multirow[t]{2}{*}{ Tm } \\
\hline & & Accession no. & & & \\
\hline \multirow[t]{2}{*}{ Beta-ACTIN } & Actin beta & NM_001314342.1 & 5' - GGAATCGTCCGTGACATCAA -3' & 107 & 58 \\
\hline & & & 5' - AGCTCGTAGCTCTTCTCCA -3' & & \\
\hline \multirow[t]{2}{*}{ BMP4 } & Bone morphogenetic protein 4 & XM_013967192.2 & 5' - AGATGGTAGTGGAGGGATGT -3’' & 111 & 62 \\
\hline & & & 5' - GTGAGTAGTGGATGGGATGTG -3’ & & \\
\hline \multirow[t]{2}{*}{ CDK6 } & Cyclin-dependent kinase 6 & XM_018047425.1 & 5' - CTCCAGTCCCACAATCCTAAC -3 & 120 & 62 \\
\hline & & & 5' - CGTCTCAGTGATGGAGAAGAAC -3 & & \\
\hline \multirow[t]{2}{*}{ CTNNB1 } & Catenin beta-1 & XM_018066894.1 & 5' - GAGGACAAGCCACAGGATTAT -3' & 101 & 58 \\
\hline & & & 5' - CCAAGATCAGCGGTCTCATT -3' & & \\
\hline \multirow[t]{2}{*}{ C-JUN } & AP-1 transcription factor subunit JUN & XM_018044742.1 & 5'-CGAAGTGACGGACTGTTCTATG -3' & 134 & 62 \\
\hline & & & 5'-TCATGCTCTGCTTCAGAATCTT -3' & & \\
\hline \multirow[t]{2}{*}{ C-MYC } & Myelocytomatosis oncogene Tag & XM_018058563.1 & 5'-CAGAGGAGAAACGAGCTGAAA -3 & 130 & 62 \\
\hline & & & 5'-CTTGGACCGACAGGATGTATG -3 & & \\
\hline \multirow[t]{2}{*}{ CYCLIND1 } & Cyclin D1 (CCND1) & XM_018043271.1 & 5'-GCAGTCTTAGGCATCCTGTAT -3 & 131 & 58 \\
\hline & & & 5'-CCTAGCCGAGAGGTTACATTA- 3 & & \\
\hline \multirow[t]{2}{*}{ LEF1 } & Lymphoid enhancer binding factor 1 & NM_001285746.1 & 5' - CAGGTGGTGTTGGACAGATAA -3' & 95 & 62 \\
\hline & & & 5' - ATGAGGGATGCCAGTTGTG -3' & & \\
\hline \multirow[t]{2}{*}{$\operatorname{ROR} \alpha$} & RAR related orphan receptor alpha & NM_001285652.1 & 5' - CTाCACCAACGGAGAGACTT -3' & 124 & 62 \\
\hline & & & 5' - GTTATCTGCTGGAGCTCTTCTC -3' & & \\
\hline \multirow[t]{2}{*}{ TCF4 } & Transcription factor 4 & XM_018039407.1 & 5' - CACTTTCCCTAGCTCCTTCTTC -3' & 136 & 62 \\
\hline & & & 5' - GTAGCTGCTAGACTGTGGAATG -3' & & \\
\hline \multirow[t]{2}{*}{ NOGGIN } & Noggin & XM_013971792.2 & 5' - GCCAGCACTATCTCCACATC -3' & 110 & 62 \\
\hline & & & 5' - CTCGTTCAGATCCTTCTCCTTG -3' & & \\
\hline
\end{tabular}

under an Olympus fluorescence microscope imaging system, and the fluorescence intensity data was analyzed with ImageJ.

\section{Real-Time Quantitative PCR Analysis}

Total RNA was extracted from the cells exposed to melatonin using Trizol and dispersed in RNase-free water. Then the first cDNA strands were obtained using a PrimeScript ${ }^{\mathrm{TM}} \mathrm{RT}$ reagent kit with gDNA Eraser (Takara, Cat\# RR047A). Gene-specific primers for amplification were designed using Primer 5 software and shown in Table 2. Real-time quantitative PCR (RT-qPCR) was performed with a Roche LightCycler ${ }^{\circledR} 96$ System using TB Green Premix Ex Taq ${ }^{\text {TM }}$ II (Takara, Cat\#RR820A). The RT-qPCR protocol was as follows: $95^{\circ} \mathrm{C}$ for $3 \mathrm{~min}$, followed by 45 cycles of $95^{\circ} \mathrm{C}$ for $15 \mathrm{~s}$ and $\mathrm{Tm}$ value for $30 \mathrm{~s}$.

\section{Western Blotting}

Cell samples were lysed in RIPA buffer. Protein concentration was detected using a BCA kit (Solarbio, Cat\#PC0020). Nuclear and cytoplasmic proteins of gsHFSCs were extracted using a Nuclear and Cytoplasmic Protein Extraction Kit (Sangon Biotech, Cat\#C510001). GAPDH and $\beta$-Actin were used as the control. Aliquots of $50 \mu \mathrm{L}$ of antigen per sample were loaded onto $8 \%$ SDS polyacrylamide electrophoresis gels. Then the gels were transferred to a polyvinylidene fluoride (PVDF) membrane at $300 \mathrm{~mA}$ for $1.5 \mathrm{~h}$, at $4^{\circ} \mathrm{C}$. Subsequently, the membranes were blocked with $5 \%$ BSA for $1 \mathrm{~h}$ at RT. The membranes were incubated with primary antibodies diluted at 1:500 in $0.1 \%$ Tween-20 in TBS (TBST) with $1 \%$ BSA overnight at $4^{\circ} \mathrm{C}$. The next day, the blots were incubated with HRP-labeled secondary goat anti-rabbit or donkey anti-rabbit $\mathrm{Ab}$ for $1 \mathrm{~h}$ at RT and imaged after chromogenic reaction.

\section{MTT Assay}

The gsHFSCs were seeded in 96-well plates at $2 \times 10^{3}$ cells/well and cultured for $72 \mathrm{~h}$ after melatonin treatments. Then, $50 \mu \mathrm{L}$ MTT solution [3-(4, 5-dimethylthiazol-2-yl)-2, 5diphenyltetrazolium bromide, $5 \mathrm{mg} / \mathrm{mL}$ ] was added to each well and the cells were incubated at $37^{\circ} \mathrm{C}$ for $4 \mathrm{~h}$ in the dark. To each solution, $100 \mu \mathrm{L}$ of DMSO was added to dissolve the precipitate and blend in the dark at RT for $15 \mathrm{~min}$. Absorbance values were determined at $490 \mathrm{~nm}$ and $630 \mathrm{~nm}$ using a multiwell microplate reader.

\section{Cell Cycle Detection}

Trypsin digested gsHFSCs were fixed with cold 70\% ethanol overnight. Cells were resuspended in $100 \mu \mathrm{L}$ PBS after low speed centrifugation, then treated with $5 \mu \mathrm{L}$ PI stain (Sangon, Cat\# E607306) containing Rnase A (Beyotime, Cat\# ST579) at $37^{\circ} \mathrm{C}$ for $30 \mathrm{~min}$. The cells were immediately placed in a CytoFLEX flow cytometer and $\sim 20,000$ cells were collected for analysis. Data were analyzed using a CytExpert system.

\section{Statistical Analysis}

SPSS (v.20) was used for statistical analysis. Comparisons between groups were tested by one-way ANOVA and LSD tests. All groups were compared with each other for every parameter 
TABLE 2 | List of antibodies used for Immunofluorescence analysis and western blot.

\begin{tabular}{|c|c|c|c|}
\hline Whole name & Name of antibody & Manufacturer & Cat No. \\
\hline Actin beta & Anti-ACTB rabbit polyclonal antibody & Sangon Biotech & D110001 \\
\hline Bone morphogenetic protein 4 & Anti-BMP4 rabbit polyclonal antibody & Sangon Biotech & D120315 \\
\hline Catenin beta 1 & Anti-CTNNB1 rabbit polyclonal antibody & Sangon Biotech & D260137 \\
\hline Cyclin-D1 & Anti-CCND1 rabbit polyclonal antibody & Sangon Biotech & D120509 \\
\hline Cyclin-dependent kinase 6 & Anti-CDK6 rabbit polyclonal antibody & Sangon Biotech & D120398 \\
\hline Glyceraldehyde-3-phosphate dehydrogenase & Anti-GAPDH rabbit polyclonal antibody & Sangon Biotech & D110016 \\
\hline Hematopoietic progenitor cell antigen CD34 & Anti-CD34 rabbit polyclonal antibody & Sangon Biotech & D263155 \\
\hline Jun proto-oncogene & Anti-JUN rabbit polyclonal antibody & Sangon Biotech & D220068 \\
\hline Lymphoid enhancer binding factor 1 & Anti-LEF1 rabbit polyclonal antibody & Cell signaling & 2286 \\
\hline Myelocytomatosis oncogene Tag & Anti-c-Myc Tag rabbit polyclonal antibody & Sangon Biotech & D110006 \\
\hline NogginOrganic cation/carnitine transporter 4 & Anti-NOG rabbit polyclonal antibodyRecombinant Anti-Oct4 antibody & Sangon Biotechabcam & D263592ab200834 \\
\hline RAR related orphan receptor alpha & Anti-RORA rabbit ployclonal antibody & Sangon Biotech & D162141 \\
\hline Transcription factor 4 & Anti-TCF4 rabbit polyclonal antibody & Sangon Biotech & D154040 \\
\hline
\end{tabular}

(mean \pm SEM) and the differences were considered significant at ${ }^{*} p<0.05,{ }^{* *} p<0.01$, and ${ }^{* * *} p<0.001$.

\section{RESULTS}

\section{Melatonin Activated Wnt Signaling Pathway in gsHFSCs With an Increment of CTNNB1 Levels in Nuclei}

Catenin beta-1, which is crucial for transmitting Wnt signals from the cytomembrane to the nucleus, was determined after $36 \mathrm{~h}$ of melatonin exposure. Immunofluorescence and RTqPCR results suggested that melatonin mediated the activation of the Wnt pathway in gsHFSCs by modulating CTNNB1. The expression of CTNNB1 showed a concentration-related increase and then reduced with increasing doses of melatonin (Figure 1A). In particular, the expression of CTNNB1 reached a maximum value at $500 \mathrm{ng} / \mathrm{L}$, then abated with melatonin dosages over $1,000 \mathrm{ng} / \mathrm{L}$ (Figure 1B). In addition, more CTNNB1 became assembled in nuclei after melatonin exposure (Figure 1C), and melatonin significantly increased the CTNNB1 levels in nuclei (Figure 1D). Discrepant CTNNB1 was probed under different melatonin concentrations, which suggested that 250 500 ng/L melatonin maintained high nuclear CTNNB1 levels in gsHFSCs (Figure 1E).

\section{Extended Melatonin Exposure Maintained the Continuous Activation of Wnt Signaling in gsHFSCs}

Since melatonin significantly increased the expression of CTNNB1, longer melatonin exposure times were implemented to explore whether the activation of Wnt signals could be maintained at $500 \mathrm{ng} / \mathrm{L}$. The result showed that CTNNB1 was not affected at $24 \mathrm{~h}$, but it was dramatically increased when exposure times were extended from 36 to $84 \mathrm{~h}$ (Figures 2A,B). At $72 \mathrm{~h}$, the protein level of CTNNB1 significantly increased and more CTNNB1 entered the nuclei, which indicated that longer exposure time might induce the migration of CTNNB1
(Figures 2C,D). Subsequently, when prolonging the stimulation time of melatonin, CTNNB1 in nuclei was maintained at a high level compared with the control (Figure 2E).

\section{Melatonin Promoted the Expression of Wnt Downstream Factors in gsHFSCs}

Catenin beta-1 always works as part of the CTNNB1/TCF/LEF enhancer factor and mediates downstream factor transcription. Therefore, the levels of two important factors-TCF4 and LEF1were determined to explore whether the complex binding was affected by melatonin. The expression of CTNNB1 was mediated at $36 \mathrm{~h}$, but melatonin did not concurrently regulate TCF4 or LEF1 at mRNA level. The expression of TCF4 was increased by melatonin exposure, but LEF1 remained constant until $72 \mathrm{~h}$ (Figure 3A). Results from immunofluorescence and Western blotting also supported these findings (Figures 3B,C). Together, these data established that extending melatonin exposure time helped to maintain the activation of Wnt in gsHFSCs.

\section{Melatonin Promoted the Proliferation and Cell Cycle of gsHFSCs Through Stimulating Wnt Downstream Factors}

Cell viability assays were performed using the MTT assay to determine whether activation of the Wnt pathway was sufficient to promote the proliferation of gsHFSCs. The proliferation of gsHFSCs was increased after $72 \mathrm{~h}$ of melatonin exposure when compared with the control cells (Figure 4A). Cell cycle analysis further showed that the percentage of gsHFSCs in $\mathrm{S}$ phase and G2 phase were higher than those in unexposed cells (Figure 4B). Moreover, to explore the possible mechanism of melatonin in regulating the proliferation of gsHFSCs, the expression of downstream factors in the Wnt pathway and cell cycle-mediated factors, such as C-JUN, C-MYC, CYCLIND1, and CDK6 were analyzed by RT-qPCR and immunofluorescence staining after $72 \mathrm{~h}$ of melatonin exposure. The mRNA of C-JUN and $C$ MYC basically showed the same trend, but CYCLIND1 was up-regulated significantly (Figure 4C). Higher protein levels of 


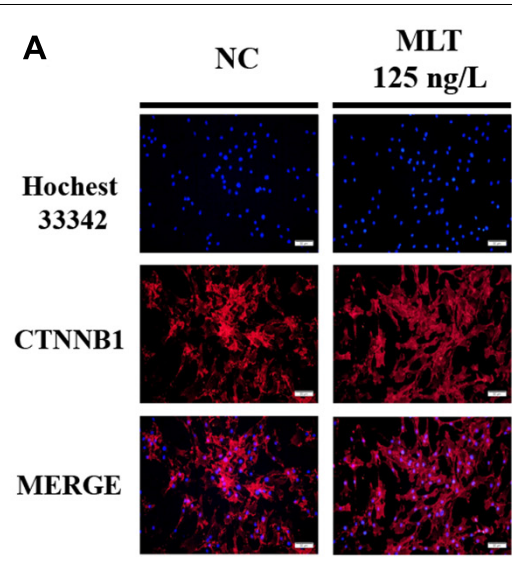

B

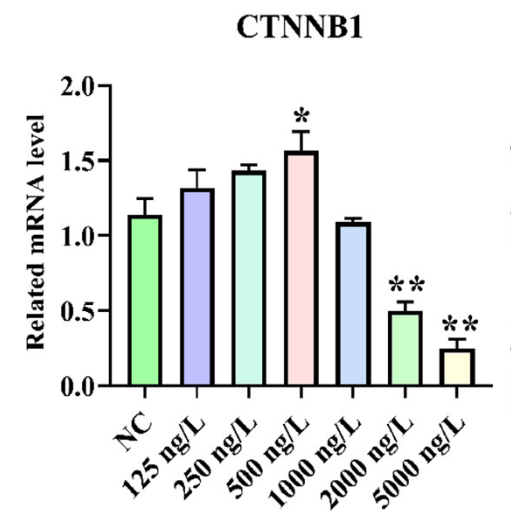

c
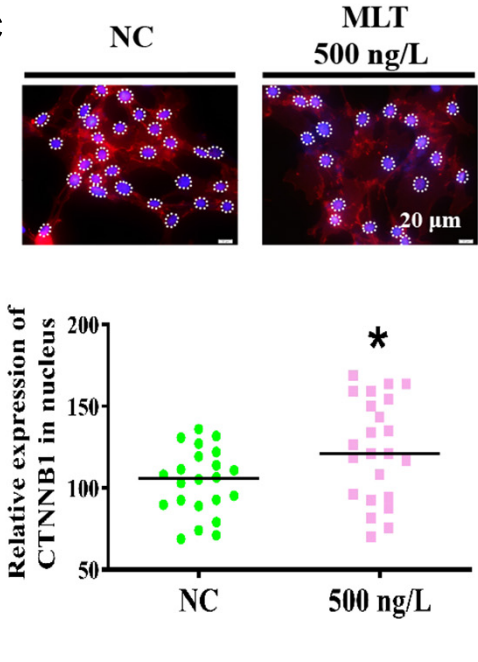

D

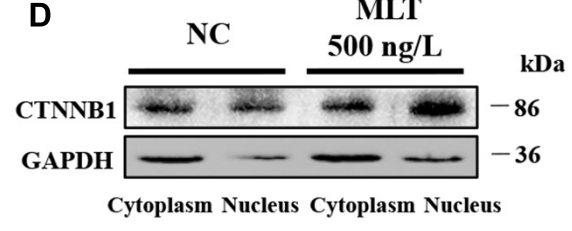

E

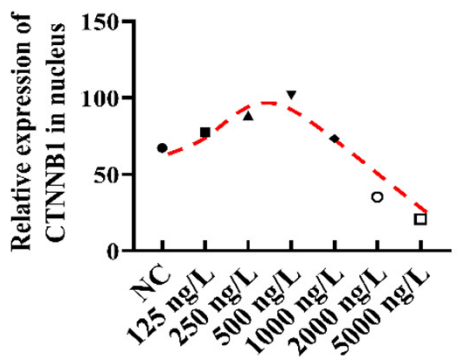

FIGURE 1 | Melatonin activated Wnt signaling pathway in gsHFSCs. (A) CTNNB1 detected by immunofluorescence staining after stimulation with different concentrations of melatonin. Scale bar, $50 \mu \mathrm{m}$. (B) Relative mRNA level of CTNNB1 by RT-qPCR; ${ }^{*} p<0.05$, ${ }^{* *} p<0.01$. (C) CTNNB1 marked by immunofluorescence in gsHFSCs. Scale bar, $20 \mu \mathrm{m}$ (white circles circumscribe the position of CTNNB1 in the nuclei), and relative immunofluorescence intensity of CTNNB1 in the nuclei; * $p<0.05$. (D) CTNNB1 in nuclei/cytoplasm as detected by Western blotting. (E) Fluorescence density analysis of CTNNB1 in the nuclei of gsHFSCs.

C-JUN, C-MYC, and CYCLIND1 were detected, but Cyclindependent kinase 6 (CDK6) remained constant after melatonin exposure (Figure 4D). These findings revealed that melatonin promoted the cell cycle by stimulating Wnt activation and might serve as a potential proliferation regulator in gsHFSCs.

\section{Melatonin Affected the Expression of $\mathrm{ROR} \alpha$ and Mediated the Equilibrium Between BMP4 and NOGGIN}

To explore the regulation of the mechanism of melatonin in gsHFSCs, the melatonin receptors MT1, MT2, and $\mathrm{ROR} \alpha$, were measured in melatonin exposed gsHFSCs. The mRNA expressions of MT1 and MT2 were not detected in gsHFSCs (not shown). But the background expression level of $R O R \alpha$ was clearly observed (Figures $\mathbf{5 A - C}$ ). A sluggish rise in $\mathrm{ROR} \alpha$ was observed in 36-h-melatonin-exposed gsHFSCs, but was not noticeable at $72 \mathrm{~h}$ (Figure 5A). The data from Western blotting and RT-qPCR supported a similar conclusion (Figures 5B,C). BMP4 and NOGGIN (a BMP antagonist) were highly related to the differentiation and pluripotency of gsHFSCs. Less BMP4 was detected in the control cells, but melatonin significantly increased its expression at 36 and $72 \mathrm{~h}$ (Figures 5A-C). Slightly different from BMP4, NOGGIN was constantly expressed in gsHFSC; a clear accumulation was noted when extending the melatonin exposure time, which suggested that melatonin always suppressed the signal of BMP4 by promoting the expression of NOGGIN (Figures 5A-C). Macroscopic details of ROR $\alpha$, BMP4, and NOGGIN were delineated by fluorescence intensity analysis under different melatonin conditions (Supplementary Figures 1A-C). ROR $\alpha$ was not notably affected by an increase in melatonin dosage, but BMP4 and NOGGIN exhibited a dramatic improvement (Figures 5D-F). In addition, the expression of BMP4 and NOGGIN were time-dependent; they were increased by melatonin and always maintained a higher level than those in untreated gsHFSCs (Figures 5D-F). These data suggested 
A

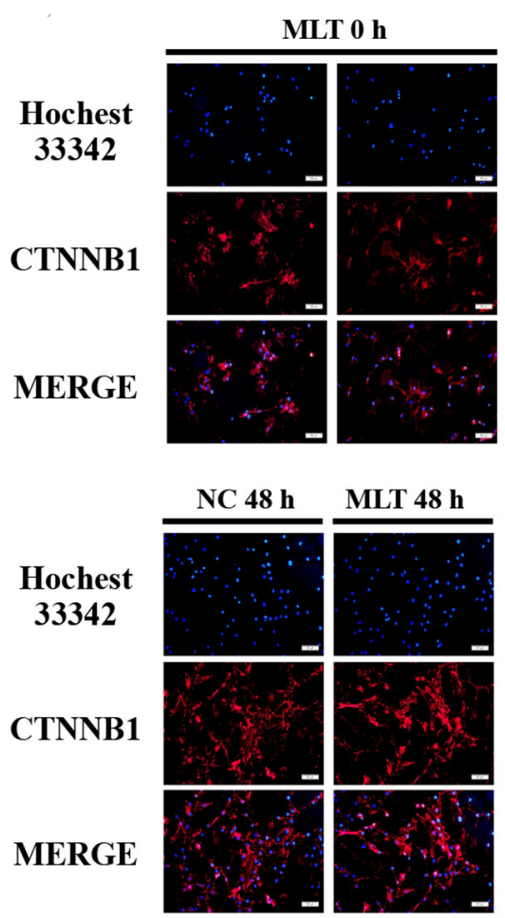

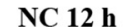
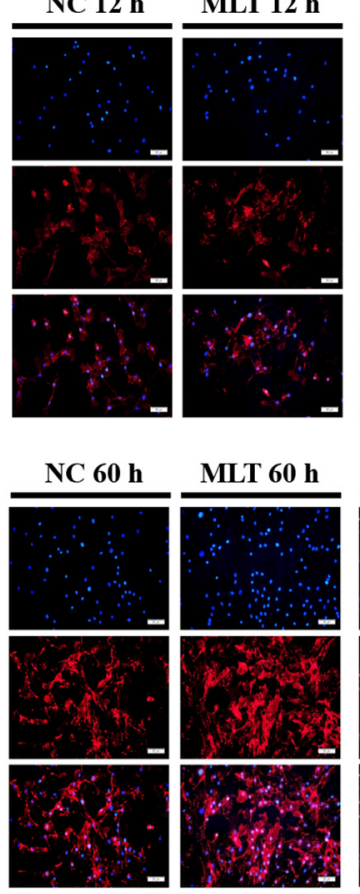

C
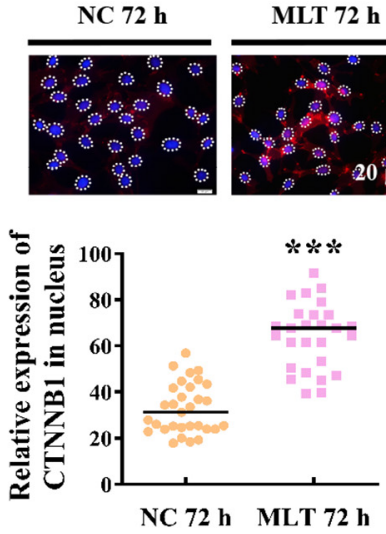
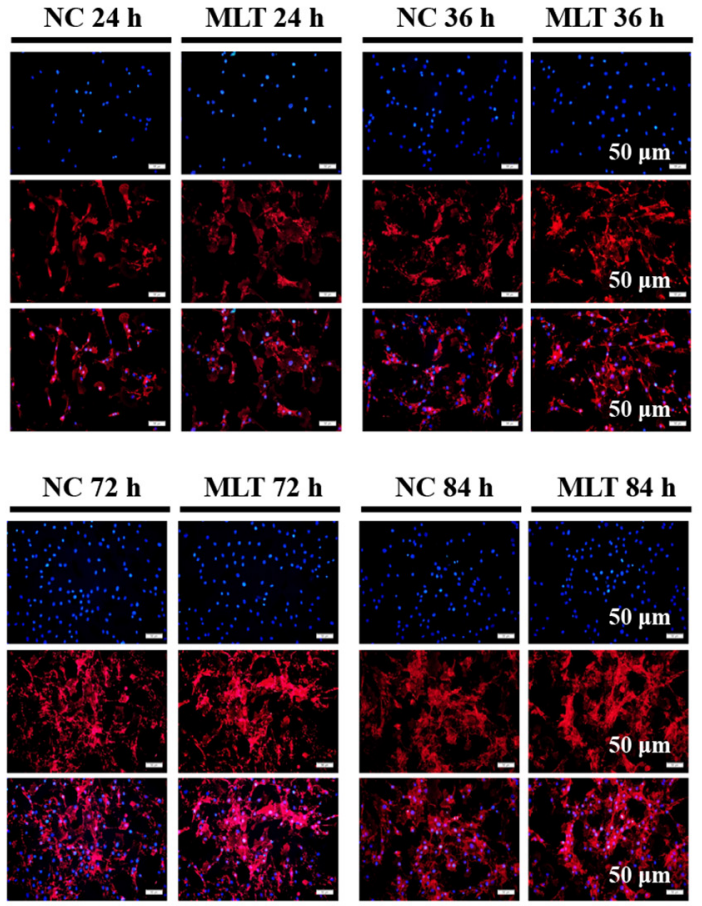

B

CTNNB1

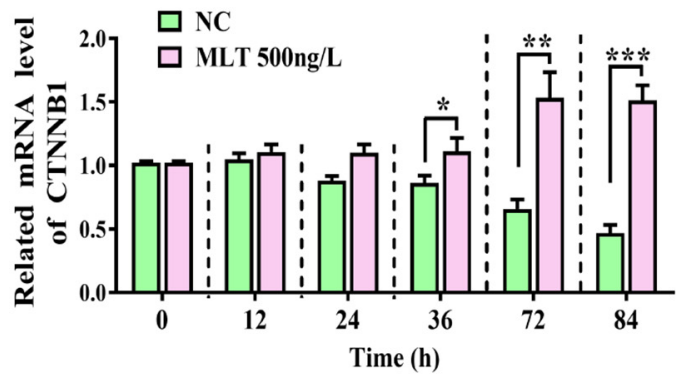

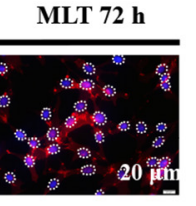
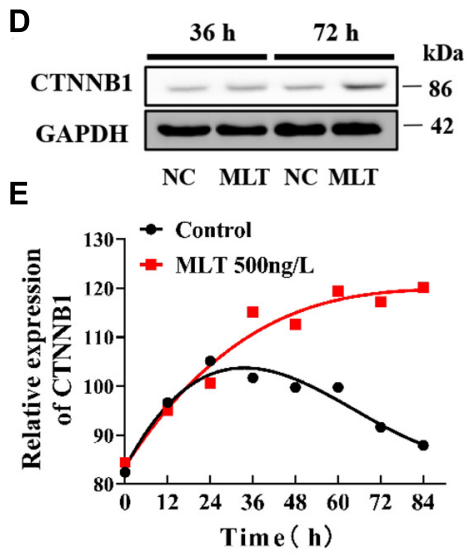

FIGURE 2 | Melatonin maintained the continuous activation of Wht signaling in gsHFSCs. (A) CTNNB1, as detected by immunofluorescence staining after stimulation by different periods of melatonin exposure. Scale bar, $50 \mu \mathrm{m}$. (B) Relative mRNA levels of CTNNB1 (Control: green; melatonin: pink); ${ }^{\star} p<0.05$, ${ }^{* *} p<0.01$. (C) CTNNB1 marked by immunofluorescence in gsHFSCs. Scale bar, $20 \mu \mathrm{m}$ (white circles circumscribe the position of CTNNB1 in the nuclei), and relative immunofluorescence intensity of CTNNB1 in nuclei; ${ }^{* \star} p<0.001$. (D) Protein levels of CTNNB1 between 36 and $72 \mathrm{~h}$ in treated gsHFSCs as shown by Western blotting. (E) Fluorescence density analysis of CTNNB1 in the nuclei of gsHFSCs after stimulation with different periods of melatonin exposure.

that the pluripotency of gsHFSCs was regulated by the dynamic equilibrium of BMP4 and NOGGIN.

\section{Melatonin Meliorated the Pluripotency of gsHFSCs by Stimulating the Three Factors of NANOG, OCT4, and CD34}

For further analysis of the function of melatonin on hair follicle stem cell pluripotency, three stemness-related transcription factors-OCT4, NANOG, and CD34-were evaluated. NANOG and OCT4 were highly related to the self-renewal of stem cells. They were gradually increased in melatonin exposed cells, but the stemness marker CD34 was not affected (Figure 6). To clarify how melatonin mediated the pluripotency of gsHFSCs, NOGGIN was overexpressed in gsHFSCs. The results showed that CTNNB1 was significantly promoted, and the expression of NANOG and OCT4 revealed a similar rise to that in melatonin exposed cells. In the co-treatment group, the cumulation of CTNNB1 was observed clearly, but BMP4 expression was reduced. Furthermore, NANOG, OCT4, and CD34 were all 
A

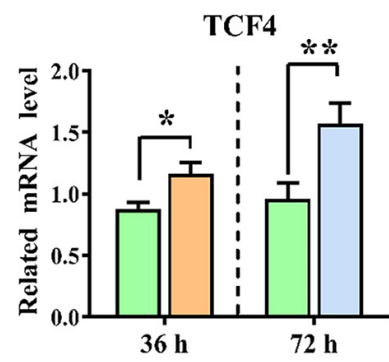

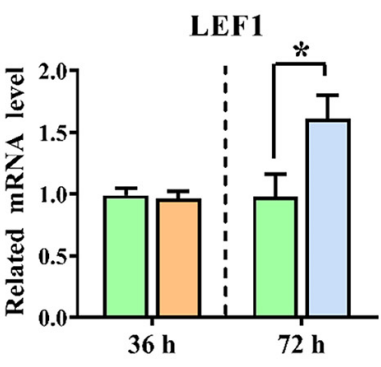

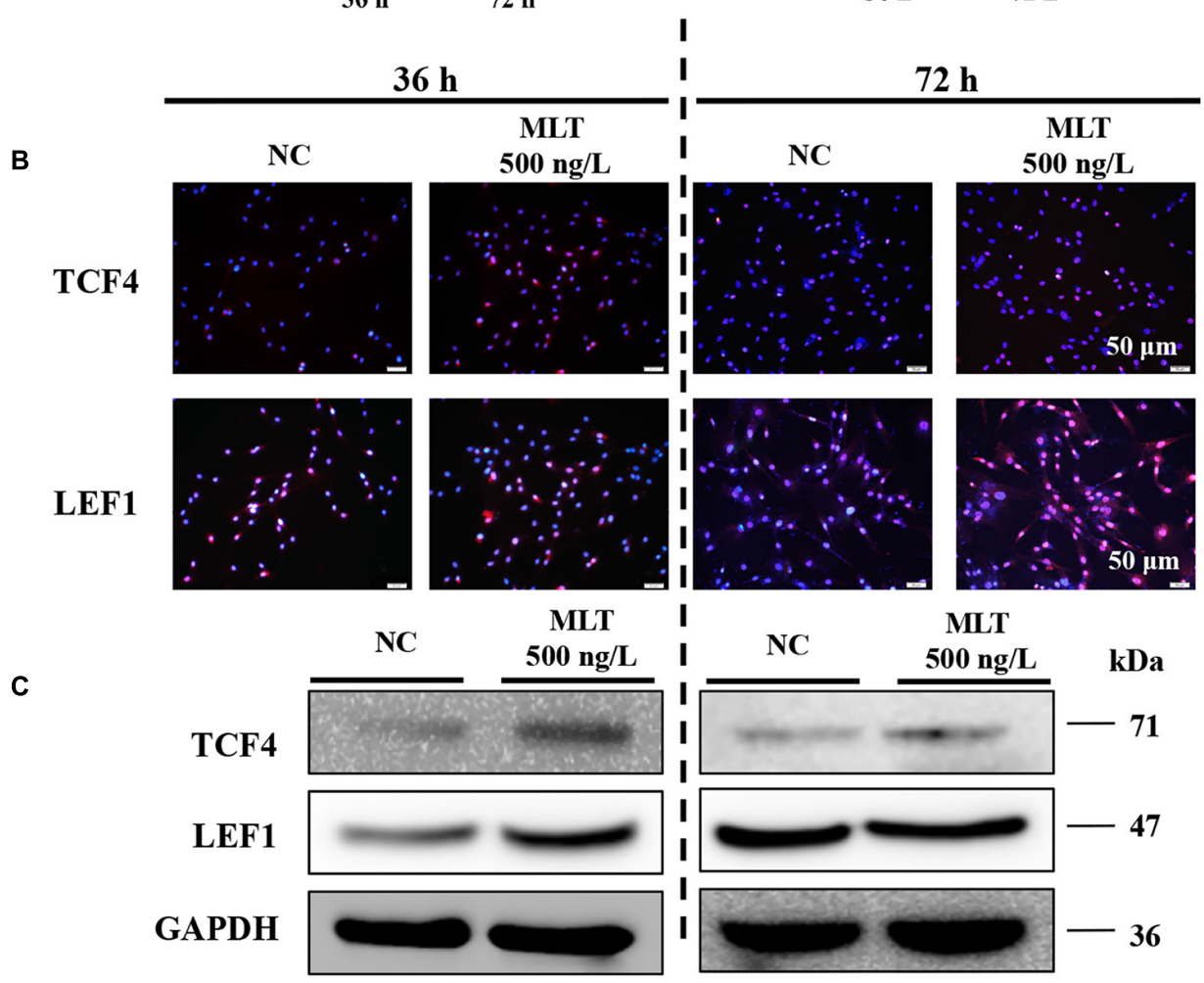

FIGURE 3 | Melatonin promoted the expression of Wnt downstream factors in gsHFSCs. (A) Relative mRNA level of TCF4 and LEF1 as detected by RT-qPCR; ${ }^{* \star} p<0.01,{ }^{\star} p<0.05$ (Control: green; $36 \mathrm{~h}$ melatonin: orange; $72 \mathrm{~h}$ melatonin: blue). (B) TCF4 and LEF1 tested by immunofluorescence staining. Scale bar, $50 \mu \mathrm{m}$. (C) TCF4 and LEF1 were compared between melatonin exposed and control cells using Western blotting.

maintained at a high level. Together, our data suggest that melatonin regulates gsHFSCs plurpotency by promoting the expression of NOGGIN (Figure 7).

\section{DISCUSSION}

The growth of cashmere is affected by many factors, such as photoperiod, nutritional aspects, feeding management, and environmental climate; these can be manipulated by farmers to control the process of cashmere growth and thus promote its production from Cashmere goats (Mcgregor, 1998; McGregor, 2009; Liu et al., 2016; Zhang et al., 2016; Yang et al., 2017). Among these factors, the control of photoperiod is considered to be the easiest and most cost-effective way to enhance cashmere production (Zhang et al., 2019b). Short duration sunlight accelerates the growth of cashmere, while long duration sunshine decelerates it (Chong et al., 2019). The mechanism of sunshine-mediated cashmere growth has, however, remained perplexing, although evidence suggests that melatonin might be a functional regulator in this process (Emesih et al., 1993). In vivo experiments have shown that cashmere growth can be increased by the implantation of subcutaneous melatonin (Sejian and Srivastava, 2010; Ghosh et al., 2014; Yang et al., 2019a,b). However, until recently, there has been little evidence to show that melatonin directly affects hair follicles. In 2018, an in vitro study revealed that specific hair follicle growth was observed in media containing $500 \mathrm{ng} / \mathrm{L}$ melatonin, which was considered to be the result of melatonin-mediated gsHFSCs proliferation (Ge et al., 2018).

Wnt signaling is closely related to cell fate determination, which is involved in stem cell proliferation, migration, and differentiation processes (Tang et al., 2019). So, this study mainly focused on CTNNB1 (a downstream signal molecule 
A

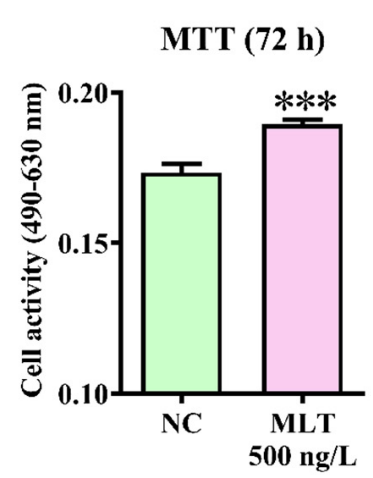

B

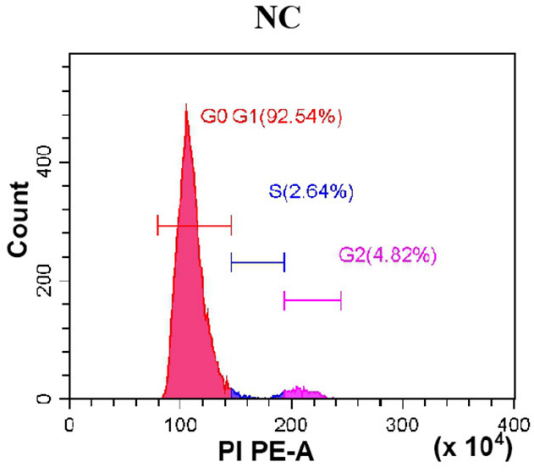

MLT

500 ng/L

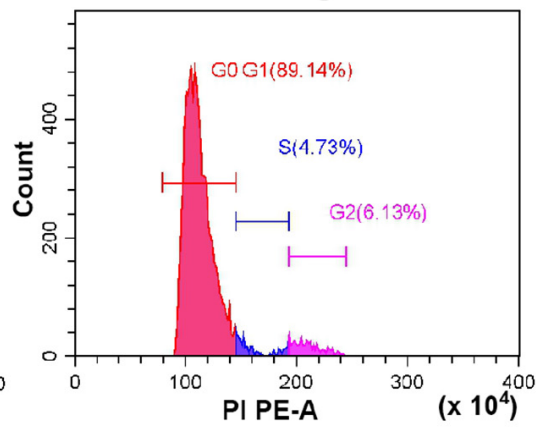

C

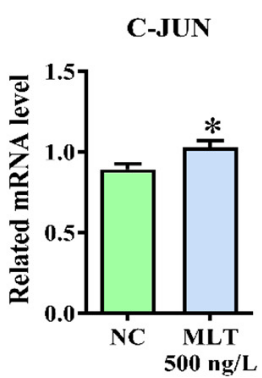

CYCLIND1

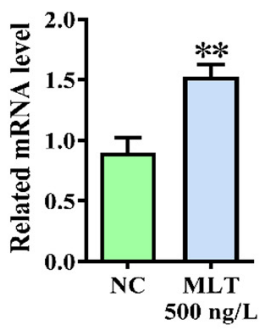

D

C-MYC

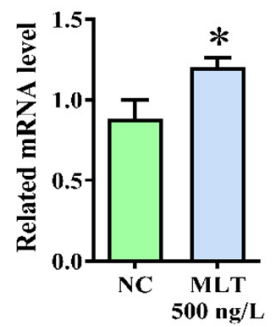

CDK6

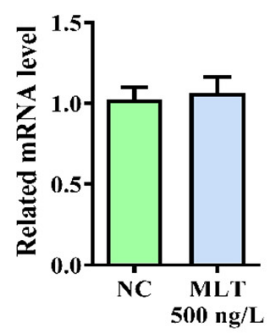

C-JUN

MLT $500 \mathrm{ng} / \mathrm{L}$

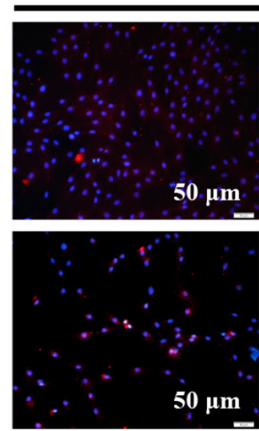

C-MYC
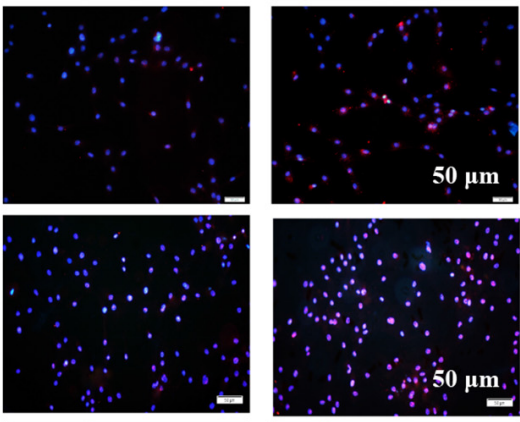

CYCLIND1
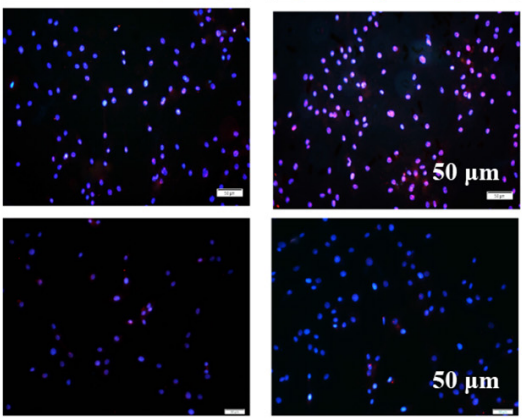

FIGURE 4 | Melatonin promoted the proliferation and cell cycle of gsHFSCs by promoting Wnt downstream factor expression, ${ }^{* * *} p<0.001$. (A) MTT analysis of melatonin on gsHFSCs proliferation following $72 \mathrm{~h}$ of exposure. (B) Cell cycle analysis of gsHFSCs after melatonin exposure at $72 \mathrm{~h}$. (C) Relative mRNA level of C-JUN, C-MYC, CYCLIND1, and CDK6 as detected by RT-qPCR after melatonin exposure for $72 \mathrm{~h} ;{ }^{* *} p<0.01,{ }^{*} p<0.05$ (Control: green; $72 \mathrm{~h}$ melatonin: blue). (D) Proteins tested by immunofluorescence staining. Scale bar, $50 \mu \mathrm{m}$.

in the Wnt pathway), which is a key regulator in stem cell proliferation and self-renewal (Augustin, 2015; Veltri et al., 2018). We found that CTNNB1 mediated the physiological role of melatonin in a manner dependent on melatonin concentration and exposure time. CTNNB1 migrated into the nuclei and promoted the expression of the downstream genes. We observed that melatonin caused the discrepant expression of CTNNB1 when concentrations were $>500 \mathrm{ng} / \mathrm{L}$; this suggested that a threshold probably existed in the different response of melatonin functions (Shen et al., 2017; Knani et al., 2020). In cashmere growth, the proliferation of gsHFSCs is a prerequisite, but the stemness of gsHFSCs reduces with the extension of cell culture time (Zhang Y. et al., 2013). So, in the current study, we determined to detect whether melatonin could activate CTNNB1 in a sustainable manner. A stable activation of Wnt was discovered in melatonin exposed gsHFSCs, which could continue for over $72 \mathrm{~h}$ and help to maintain the proliferation and self-renewal of gsHFSCs. Wnt downstream factors TCF4 and/or LEF1, which are associated with dedifferentiation and acquisition of stemness properties (Merrill et al., 2001; Kim et al., 2020), became bound to CTNNB1 to co-regulate downstream gene expression (Dasgupta and Fuchs, 1999). Alteration of TCF4 and LEF1 in the current study also suggested that Wnt activation was the key to regulating melatonin-mediated cashmere growth. It has been shown that a high expression of TCF4 and LEF1 inhibits stem cell differentiation, which also plays important roles in skin 
A
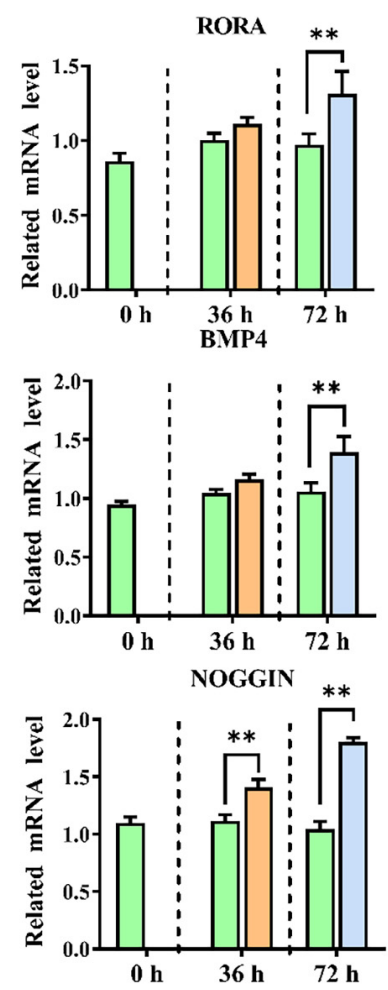

D
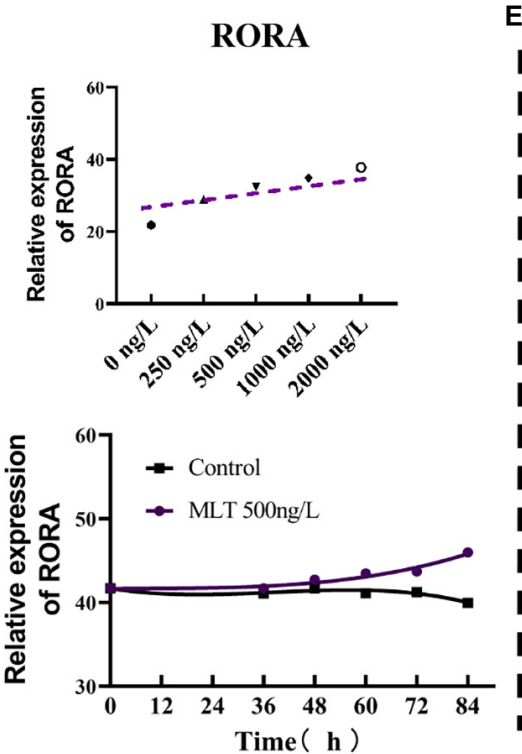

B

BMP4

NOGGIN
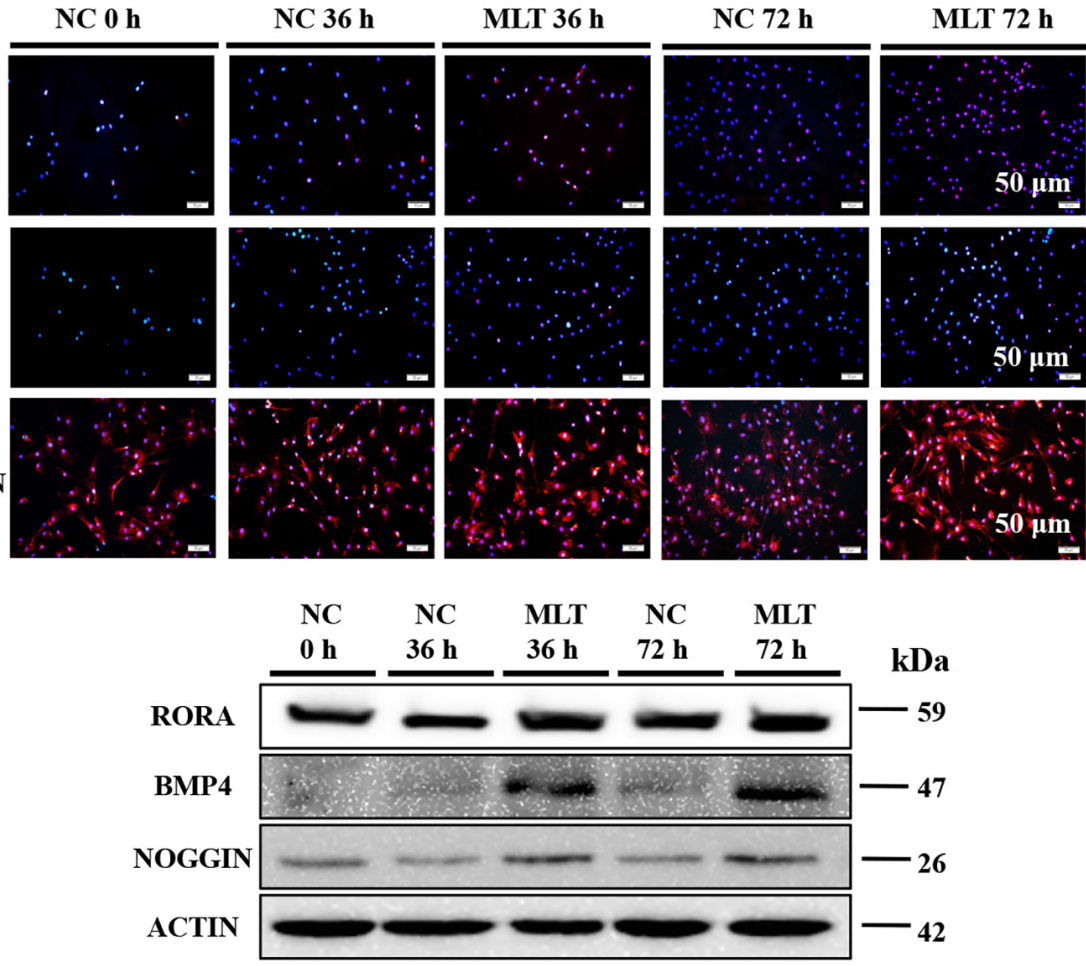

\section{E}

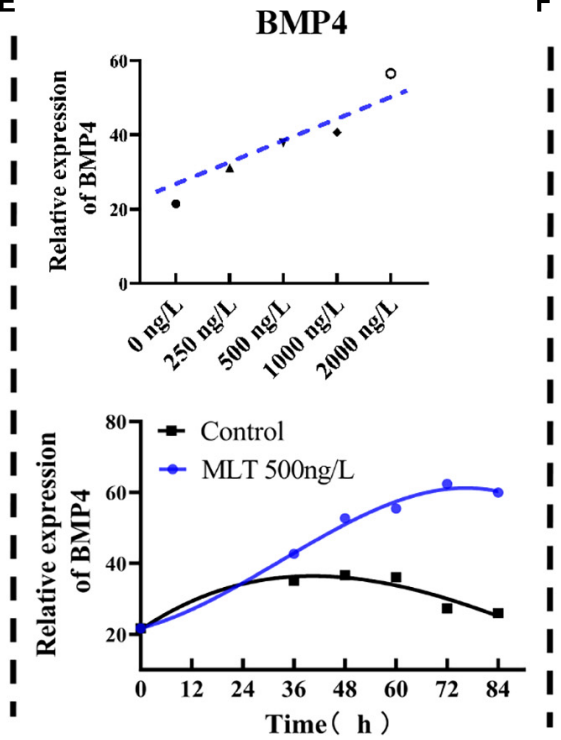

F

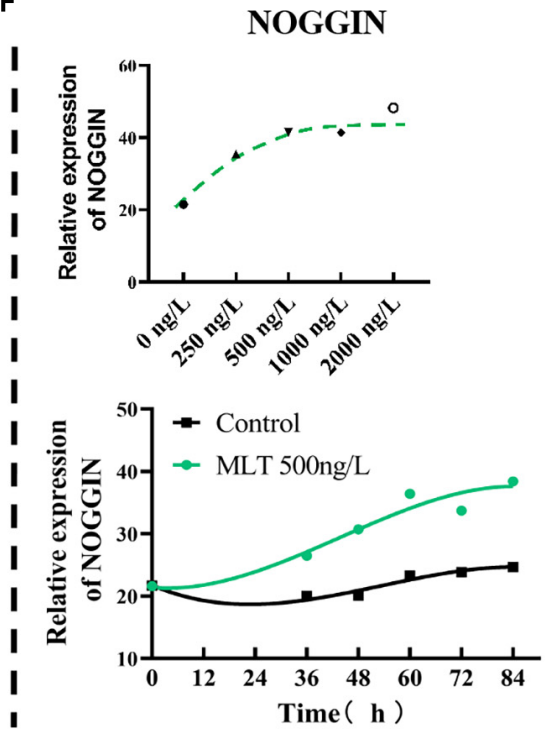

FIGURE 5 | Melatonin mediated the expression of ROR $\alpha$, BMP4, and NOGGIN. (A) Relative mRNA levels of ROR $\alpha$, BMP4, and NOGGIN in gsHFSCs before/after melatonin exposure (Control: green; $36 \mathrm{~h}$ melatonin: orange; $72 \mathrm{~h}$ melatonin: blue); ${ }^{* *} p<0.01$. (B) Protein levels of ROR $\alpha$, BMP4, and NOGGIN in gsHFSCs as revealed by immunofluorescence staining. Scale bar, $50 \mu \mathrm{m}$. (C) Protein levels of ROR $\alpha$, BMP4, and NOGGIN in gsHFSCs as shown by Western blotting. (D) Fluorescence intensity analysis of ROR $\alpha$ in melatonin exposed gsHFSCs. (E) Fluorescence intensity analysis of BMP4 in melatonin exposed gsHFSCs. (F) Fluorescence intensity of NOGGIN in melatonin exposed gsHFSCs.

regeneration and hair follicle formation (Aulicino et al., 2020; Yu N. et al., 2020). In this study, we demonstrated that melatonin might activate Wnt signals in gsHFSCs depending on the strength and duration of CTNNB1 signals, which has been detected in other melatonin exposed cells (Celso et al., 2004; Lowry et al., 2005; Silva-Vargas et al., 2005). Wnt signaling may activate the transcription of growth-related factors and mediate the cell proliferation of HFSCs (Lien et al., 2014; Xu et al., 2015). 


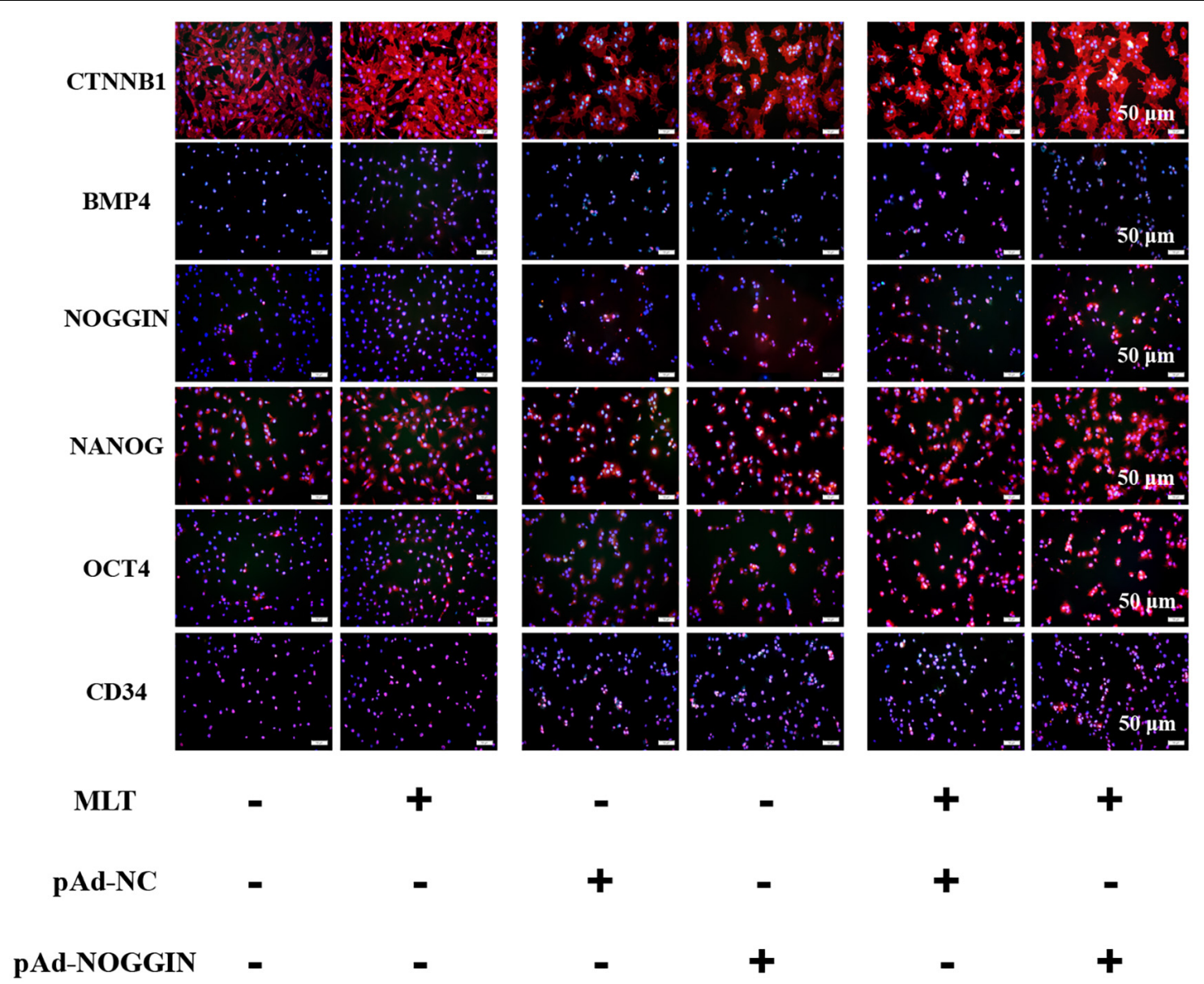

FIGURE 6 | Protein levels of CTNNB1, BMP4, NOGGIN, NANOG, OCT4, and CD34 were detected after exposure to 500 ng/L melatonin with or without NOGGIN overexpression as shown by immunofluorescence staining at $72 \mathrm{~h}$. Scale bar, $50 \mu \mathrm{m}$.

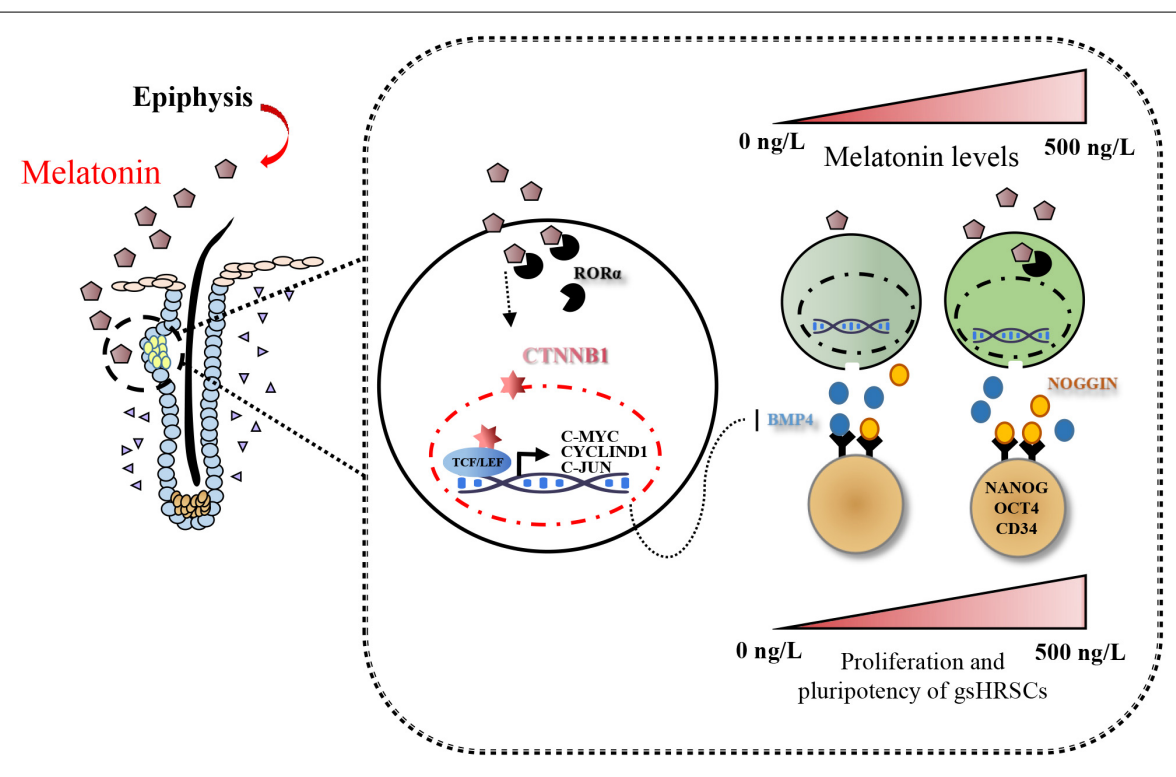


In this study, melatonin was also discovered to promote the expression of the Wnt downstream factors C-JUN, C-MYC, and CYCLIND1, which might mediate the proliferation of gsHFSCs. Melatonin propelled the cell cycle of gsHFSCs in a CYCLIND1dependent way, and it was helpful to explore this mechanism in melatonin induced cell proliferation.

The intensity of different responses to melatonin could be related to the cell-line-specific pattern of melatonin cellular receptors and cytosolic protein expression (Zaminy et al., 2008). Furthermore, it is known that the activation of melatonin is mediated by $G$ protein-coupled receptor melatonin receptor type 1, 2, and 3 (MT1, MT2, MT3, respectively, and directly) or the retinoid-related orphan nuclear receptor $\alpha(\mathrm{RZR} / \mathrm{ROR} \alpha$, indirectly), and these receptors serve as attractive targets for a series of biological processes such as immunomodulation, endocrine regulation, and cancer formation (Foldes et al., 1992; Slominski et al., 2012). In our study, MT1 and MT2 were detected, but the background expression of ROR $\alpha$ was discovered in gsHFSCs. $\mathrm{ROR} \alpha$ is reported to suppress the activation of Wnt (Lee et al., 2010). However, a contradictory result was obtained in the current study, which supported the existence of other mechanisms.

Nevertheless, we achieved a breakthrough in subsequent studies. Numerous research studies now show that the activation of Wnt is regulated by a series of signals, including BMP, FGF, and Notch pathways in HFSCs (Genander et al., 2014; Lien et al., 2014; Mesa et al., 2015; Binh et al., 2018; He et al., 2018). It is also well known that BMP4 regulates processes such as germ cell differentiation and the maintenance of self-renewing stem cells (Zhang J. et al., 2013; Kan et al., 2019). BMP4 is widely expressed in hair follicle stromal cells and the epidermis during embryonic hair follicle formation and the post-natal hair follicle cycle (Botchkarev et al., 2002). So, the expressions of BMP4 and NOGGIN were also examined here to measure the cell fate of gsHFSCs. The expression of BMP4 was notably increased in the presence of melatonin. The alteration of BMP4 is predictable here, because melatonin also mediates cell differentiation in series types of stem cells (Voeltzel et al., 2018; Zhang et al., 2018; Yu S. et al., 2020). NOGGIN works as an antagonistic protein in inhibiting the binding of BMP to its receptors (Chen et al., 2012; Xie et al., 2016); NOGGIN is also reported to maintain the pluripotency of stem cells (Chaturvedi et al., 2009; Díaz-Moreno et al., 2018). However, in the current study, NOGGIN showed an astonishing performance as a potential target of melatonin in gsHFSCs. We found that NOGGIN was overexpressed in gsHFSCs, and pluripotency markers were detected in gsHFSCs with/without melatonin exposure. The expression of NANOG was promoted under melatonin exposure and NOGGIN overexpressed gsHFSCs. In NOGGIN overexpressed gsHFSCs, melatonin magnified the acceleration of NANOG, OCT4, and CD34. NANOG participates in the

\section{REFERENCES}

Alila-Johansson, A., Eriksson, L., Soveri, T., and Laakso, M. L. (2001). Seasonal variation in endogenous serum melatonin profiles in goats: a difference transcription regulation of stem cells, but not in differentiated cells, and its ample expression meant that the stemness of cells was well maintained (Yamaguchi et al., 2005). Oct4 is known to be expressed in totipotent cells such as embryonic stem cells but its expression declines or disappears following cell differentiation (Yoo et al., 2011).

\section{CONCLUSION}

Taken together, our findings provided a comprehensive view of the action of Wnt in melatonin stimulated cells; furthermore, melatonin mediated the stemness of gsHFSCs through its regulation of NOGGIN.

\section{DATA AVAILABILITY STATEMENT}

The original contributions presented in the study are included in the article/Supplementary Material, further inquiries can be directed to the corresponding author/s.

\section{ETHICS STATEMENT}

The animal study was reviewed and approved by Laboratory Animals of the National Institutes of Health.

\section{AUTHOR CONTRIBUTIONS}

WZ and WG designed the research. WZ, NW, TZ, and MW performed the experiments and analyzed the data. WZ wrote the manuscript. XW has primary responsibility for the final content. All authors read and approved the final manuscript.

\section{FUNDING}

This work was supported by Key Project of Natural Science Basic Research Program of Shaanxi Province (No. 2019JZ-07) and the National Natural Science Foundation of China (No. 31772573).

\section{SUPPLEMENTARY MATERIAL}

The Supplementary Material for this article can be found online at: https://www.frontiersin.org/articles/10.3389/fcell.2021. 686805/full\#supplementary-material

Supplementary Figure 1 | Protein levels of RORA (A), BMP4 (B), NOGGIN (C) were detected after exposed melatonin by immunofluorescence staining. Scale bar, $50 \mu \mathrm{m}$.

between spring and fall?. J. Biol. Rhythms 16, 254-263. doi: 10.1177/ 074873040101600308

Andl, T., Reddy, S. T., Gaddapara, T., and Millar, S. E. (2002). WNT signals are required for the initiation of hair follicle 
development. Dev. Cell 2, 643-653. doi: 10.1016/s1534-5807(02) 00167-3

Augustin, I. (2015). Wnt signaling in skin homeostasis and pathology. J. Deutsch. Dermatol. Ges. 13, 302-306. doi: 10.1111/ddg. 12620

Aulicino, F., Pedone, E., Sottile, F., Lluis, F., and Cosma, M. P. (2020). Canonical Wnt pathway controls mESC Self-Renewal through inhibition of spontaneous differentiation via $\beta$-Catenin/TCF/LEF functions. Stem Cell Rep. 15, 646-661. doi: 10.1016/j.stemcr.2020.07.019

Binh, N. M., Idan, C., Vinod, K., Zijian, X., Carmit, B., Dauber-Decker, K. L., et al. (2018). Publisher correction: FGF signalling controls the specification of hair placode-derived SOX9 positive progenitors to Merkel cells. Nat. Commun. 9:2854. doi: 10.1038/s41467-018-05361-8

Botchkarev, V. A., Botchkareva, N. V., Sharov, A. A., Funa, K., Huber, O., and Gilchrest, B. A. (2002). Modulation of BMP signaling by noggin is required for induction of the secondary (nontylotrich) hair follicles. J. Investig. Dermatol. 118, 3-10. doi: 10.1046/j.1523-1747.2002.01645.x

Buchanan, B. A., Chapin, L. T., and Tucker, H. A. (1992). Prolonged suppression of serum concentrations of melatonin in prepubertal heifers. J. Pineal Res. 12, 181-189. doi: 10.1111/j.1600-079x.1992.tb00046.x

Celso, C. L., Prowse, D. M., and Watt, F. M. (2004). Transient activaton of $\beta$ catenin signalling in adult mouse epidermis is sufficient to induce new hair follicles but continuous activation is required to maintain hair follicle tumours. Development 131, 1787-1799. doi: 10.1242/dev.01052

Chaturvedi, G., Simone, P., Ain, R., Soares, M., and Wolfe, M. (2009). Noggin maintains pluripotency of human embryonic stem cells grown on Matrigel. Cell Prolif. 42, 425-433. doi: 10.1111/j.1365-2184.2009.00616.x

Chen, C., Uludağ, H., Wang, Z., and Jiang, H. (2012). Noggin suppression decreases BMP-2-induced osteogenesis of human bone marrow-derived mesenchymal stem cells in vitro. J. Cell. Biochem. 113, 3672-3680. doi: 10.1002/jcb.24240

Chong, Z. Z., Hai, Z. S., Sheng, L. L., Dan, S., Chun, H. Z., Lu, J., et al. (2019). Effects of photoperiod on nutrient digestibility, hair follicle activity and cashmere quality in Inner Mongolia white cashmere goats. Asian Austr. J. Anim. Sci. 32, 541-547. doi: 10.5713/ajas.18.0154

Dasgupta, R., and Fuchs, E. (1999). Multiple roles for activated LEF/TCF transcription complexes during hair follicle development and differentiation. Development 126:4557.

Díaz-Moreno, M., Armenteros, T., Gradari, S., Hortigüela, R., García-Corzo, L., Fontán-Lozano, Á. T., et al. (2018). Noggin rescues age-related stem cell loss in the brain of senescent mice with neurodegenerative pathology. Proc. Natl. Acad. Sci. U. S. A. 115, 11625-11630. doi: 10.1073/pnas.1813205115

Driskell, R. R., Goodheart, M., Neff, T., Liu, X., Luo, M., Moothart, C., et al. (2007). Wnt3a regulates Lef-1 expression during airway submucosal gland morphogenesis. Dev. Biol. 305, 90-102. doi: 10.1016/j.ydbio.2007.01.038

Duan, C., Xu, J., Sun, C., Jia, Z., and Zhang, W. (2015). Effects of melatonin implantation on cashmere yield, fibre characteristics, duration of cashmere growth as well as growth and reproductive performance of Inner Mongolian cashmere goats. J. Anim. Sci. Biotechnol. 6:22. doi: 10.1186/s40104-0150023-2

Emesih, G. C., Newton, G. R., Teh, T. H., and Zia, J. H. (1993). Effects of photoperiod and continuous administration of melatonin on plasma concentrations of prolactin in cashmere goats. Small Rumin. Res. 11, 247-256. doi: 10.1016/0921-4488(93)90049-N

Feng, Y., and Gun, S. (2021). Melatonin supplement induced the hair follicle development in offspring rex rabbits. J. Anim. Physiol. Anim. Nutr. 105, 167174. doi: $10.1111 /$ jpn. 13417

Foldes, A., Hoskinson, R. M., Baker, P., McDonald, B. J., Maxwell, C. A., and Restall, B. J. (1992). Effect of immunization against melatonin on seasonal fleece growth in feral goats. J. Pineal Res. 13, 85-94.

Fu, S., Zhao, H., Zheng, Z., Li, J., and Zhang, W. (2014). Melatonin regulating the expression of miRNAs involved in hair follicle cycle of cashmere goats skin. Yi Chuan 36, 1235-1242. doi: 10.3724/SP.J.1005.2014.1235

Ge, W., Wang, S. H., Sun, B., Zhang, Y. L., Shen, W., Khatib, H., et al. (2018). Melatonin promotes cashmere goat (Capra hircus) secondary hair follicle growth: a view from integrated analysis of long non-coding and coding RNAs. Cell Cycle 17, 1255-1267. doi: 10.1080/15384101.2018.1471318

Genander, M., Cook, P., Ramsköld, D., Keyes, B., Mertz, A., Sandberg, R., et al. (2014). BMP signaling and its pSMAD1/5 target genes differentially regulate hair follicle stem cell lineages. Cell stem cell 15, 619-633. doi: 10.1016/j.stem. 2014.09.009

Ghosh, S., Singh, A. K., and Haldar, C. (2014). Seasonal modulation of immunity by melatonin and gonadal steroids in a short day breeder goat capra hircus. Theriogenology 82, 1121-1130. doi: 10.1016/j.theriogenology.2014.07.035

He, N., Dong, Z., Tai, D., Hao, L., and Liu, D. (2018). The role of sox9 in maintaining the characteristics and pluripotency of arbas cashmere goat hair follicle stem cells. Cytotechnology 70, 1155-1165. doi: 10.1007/s10616-0180206-8

Huelsken, J., Vogel, R., Erdmann, B., Cotsarelis, G., and Birchmeier, W. (2001). beta-Catenin controls hair follicle morphogenesis and stem cell differentiation in the skin. Cell 105, 533-545. doi: 10.1016/s0092-8674(01)00336-1

Ishitani, T., Ninomiyatsuji, J., and Matsumoto, K. (2003). Regulation of lymphoid enhancer factor $1 / \mathrm{T}$-Cell Factor by mitogen-activated protein kinase-related nemo-like kinase-dependent phosphorylation in Wnt/ $\beta$-Catenin signaling. Mol. Cell. Biol. 23, 1379-1389. doi: 10.1128/MCB.23.4.1379-1389.2003

Johnston, J. D., and Skene, D. J. (2015). 60 YEARS OF NEUROENDOCRINOLOGY: regulation of mammalian neuroendocrine physiology and rhythms by melatonin. J. Endocrinol. 226, T187-T198. doi: 10.1530/JOE-15-0119

Kan, C., Ding, N., Yang, J., Tan, Z., McGuire, T. L., Lu, H., et al. (2019). BMPdependent, injury-induced stem cell niche as a mechanism of heterotopic ossification. Stem Cell Res. Ther. 10:14. doi: 10.1186/s13287-018-1107-7

Kim, S., Kim, H., Tan, A., Song, Y., Lee, H., Ying, Q., et al. (2020). The Distinct role of Tcfs and Lef1 in the self-renewal or differentiation of mouse embryonic stem cells. Int. J. stem cells 13, 192-201. doi: 10.15283/ijsc20044

Knani, L., Venditti, M., Kechiche, S., Banni, M., Messaoudi, I., and Minucci, S. (2020). Melatonin protects bone against cadmium-induced toxicity via activation of Wnt/beta-catenin signaling pathway. Toxicol Mech. Methods 30, 237-245. doi: 10.1080/15376516.2019.1701595

Lee, J., Kim, I., Kim, H., Lee, J., Kim, K., Yim, H., et al. (2010). RORalpha attenuates Wnt/beta-catenin signaling by PKCalpha-dependent phosphorylation in colon cancer. Mol. Cell 37, 183-195. doi: 10.1016/j.molcel.2009.12.022

Li, X., Hao, F., Hu, X., Wang, H., and Liu, D. (2019). Generation of T $\beta 4$ knockin Cashmere goat using CRISPR/Cas9. Int. J. Biol. Sci. 15, 1743-1754. doi: 10.7150/ijbs.34820

Lien, W. H., Polak, L., Lin, M., Lay, K., Zheng, D., and Fuchs, E. (2014). In vivo transcriptional governance of hair follicle stem cells by canonical Wnt regulators. Nat. Cell Biol. 16, 179-190. doi: 10.1038/ncb2903

Liu, B., Gao, F., Guo, J., Wu, D., Hao, B., Li, Y., et al. (2016). A Microarray-Based analysis reveals that a short photoperiod promotes hair growth in the Arbas cashmere goat. PLoS One 11:e0147124. doi: 10.1371/journal.pone.0147124

Lowry, E. W.,Blanpain, C., Nowak, J. A., Guasch, G., Lewis, L., and Fuchs, E. (2005). Defining the impact of beta-catenin/Tcf transactivation on epithelial stem cells. Genes Dev. 19, 1596-1611. doi: 10.1101/gad.1324905

Mcgregor, B. A. (1998). Nutrition, management and other environmental influences on the quality and production of mohair and cashmere: a review with particular reference to mediterranean and annual temperate climatic zones. Small Rumin. Res. 28, 199-215. doi: 10.1016/S0921-4488(97)00100-4

McGregor, B. A. (2009). A review of cashmere nutrition experiments with suggestions for improving their design and conduct. Small Rumin. Res. 82, 71-83. doi: 10.1016/j.smallrumres.2009.01.013

Merrill, B. J., Gat, U., DasGupta, R., and Fuchs, E. (2001). Tcf3 and Lef1 regulate lineage differentiation of multipotent stem cells in skin. Genes Dev. 15, 16881705. doi: 10.1101/gad.891401

Mesa, K. R., Rompolas, P., Zito, G., Myung, P., Sun, T. Y., and Brown, S. (2015). Niche-induced cell death and epithelial phagocytosis regulate hair follicle stem cell pool. Nature 522, 94-97. doi: 10.1038/nature14306

Nozaki, M., Tsushima, M., and Mori, Y. (1990). Diurnal changes in serum melatonin concentrations under indoor and outdoor environments and light suppression of nighttime melatonin secretion in the female Japanese monkey. J. Pineal Res. 9, 221-230. doi: 10.1111/j.1600-079x.1990.tb00710.x

Omer, C. A., Miller, P. J., Diehl, R. E., and Kral, A. M. (1999). Identification of Tcf4 residues involved in high-affinity beta-catenin binding. Biochem. Biophys. Res. Commun. 256, 584-590. doi: 10.1006/bbrc.1999.0379

O'Neill, K. T., Litherland, A. J., and Hamilton, G. (1992). Melatonin for cashmere production in breeding does. Proc. N. Z. Soc. Anim. Prod. 52, 161-164. 
Sejian, V., and Srivastava, R. S. (2010). Pineal-adrenal-immune system relationship under thermal stress: effect on physiological, endocrine, and nonspecific immune response in goats. J. Physiol. Biochem. 66, 339-349. doi: 10. 1007/s13105-010-0040-8

Shen, Z., Zhou, Z., Gao, S., Guo, Y., Gao, K., Wang, H., et al. (2017). Melatonin inhibits neural cell apoptosis and promotes locomotor recovery via activation of the Wnt/beta-Catenin signaling pathway after spinal cord injury. Neurochem. Res. 42, 2336-2343. doi: 10.1007/s11064-017-2251-7

Silva-Vargas, V., Celso, C. L., Giangreco, A., Ofstad, T., Prowse, D. M., Braun, K. M., et al. (2005). $\beta$-Catenin and Hedgehog signal strength can specify number and location of hair follicles in adult epidermis without recruitment of bulge stem cells. Dev. Cell 9, 121-131. doi: 10.1016/j.devcel.2005.04.013

Slominski, A. T., Hardeland, R., Zmijewski, M. A., Slominski, R. M., Reiter, R. J., and Paus, R. (2018). Melatonin: a Cutaneous perspective on its production, metabolism, and functions. J. Invest. Dermatol. 138, 490-499. doi: 10.1016/j.jid. 2017.10.025

Slominski, R. M., Reiter, R. J., Schlabritz-Loutsevitch, N., Ostrom, R. S., and Slominski, A. T. (2012). Melatonin membrane receptors in peripheral tissues: distribution and functions. Mol. Cell Endocrinol. 351, 152-166. doi: 10.1016/j. mce.2012.01.004

Tang, T., Guo, C., Xia, T., Zhang, R., Zen, K., Pan, Y., et al. (2019). LncCCAT1 promotes breast cancer stem cell function through activating WNT/ $\beta$-catenin signaling. Theranostics 9, 7384-7402. doi: 10.7150/thno. 37892

Van Genderen, C., Okamura, R., Fariñas, I., Quo, R., Parslow, T., Bruhn, L., et al. (1994). Development of several organs that require inductive epithelialmesenchymal interactions is impaired in LEF-1-deficient mice. Genes Dev. 8, 2691-2703. doi: 10.1101/gad.8.22.2691

Veltri, A., Lang, C., and Lien, W. H. (2018). Concise Review: wnt Signaling Pathways in Skin Development and Epidermal Stem Cells. Stem Cells 36, 22-35. doi: $10.1002 /$ stem. 2723

Voeltzel, T., Flores-Violante, M., Zylbersztejn, F., Lefort, S., Billandon, M., Jeanpierre, S., et al. (2018). A new signaling cascade linking BMP4, BMPR1A, $\triangle \mathrm{Np73}$ and NANOG impacts on stem-like human cell properties and patient outcome. Cell Death Dis. 9:1011. doi: 10.1038/s41419-018-1042-7

Xie, Z., Wang, P., Li, Y., Deng, W., Zhang, X., Su, H., et al. (2016). Imbalance between bone morphogenetic protein 2 and noggin induces abnormal osteogenic differentiation of mesenchymal stem cells in ankylosing spondylitis. Arthritis Rheumatol. 68, 430-440. doi: 10.1002/art.39433

Xiong, Y., Liu, Y., Song, Z. Q., Hao, F., and Yang, X. C. (2014). Identification of $\mathrm{Wnt} / \beta$-catenin signaling pathway in dermal papilla cells of human scalp hair follicles: TCF4 regulates the proliferation and secretory activity of dermal papilla cell. J. Dermatol. 41, 84-91. doi: 10.1111/1346-8138. 12313

Xu, Z., Wang, W., Jiang, K., Yu, Z., Huang, H., Wang, F., et al. (2015). Embryonic attenuated $\mathrm{Wnt} / \beta$-catenin signaling defines niche location and long-term stem cell fate in hair follicle. ELife 4:e10567. doi: 10.7554/eLife.10567

Yamaguchi, S., Kimura, H., Tada, M., Nakatsuji, N., and Tada, T. (2005). Nanog expression in mouse germ cell development. Gene Expr. Patterns 5, 639-646. doi: 10.1016/j.modgep.2005.03.001

Yang, C. H., Xu, J. H., Ren, Q. C., Duan, T., Mo, F., and Zhang, W. (2019b). Melatonin promotes secondary hair follicle development of early postnatal cashmere goat and improves cashmere quantity and quality by enhancing antioxidant capacity and suppressing apoptosis. J. Pineal Res. 67:e12569. doi: 10.1111/jpi.12569

Yang, C. H., Wu, Z. Y., Li, Y., and Zhang, W. (2019a). Effect of melatonin administration to lactating cashmere goats on milk production of dams and on hair follicle development in their offspring. Animal 14, 1241-1248. doi: $10.1017 /$ s 1751731119002726
Yang, M., Song, S., Dong, K., Chen, X., Liu, X., Rouzi, M., et al. (2017). Skin transcriptome reveals the intrinsic molecular mechanisms underlying hair follicle cycling in Cashmere goats under natural and shortened photoperiod conditions. Sci. Rep. 7:13502. doi: 10.1038/s41598-017-13986-w

Yoo, Y. M., Jung, E. M., Choi, K. C., and Jeung, E. B. (2011). Effect of melatonin on mRNA expressions of transcription factors in murine embryonic stem cells. Brain Res. 1385, 1-7. doi: 10.1016/j.brainres.2011.02.047

Yu, N., Hu, T., Yang, H., Zhang, L., Song, Q., Xiang, F., et al. (2020). Twist1 Contributes to the Maintenance of Some Biological Properties of Dermal Papilla Cells by Forming a Complex With Tcf4 and $\beta$-Catenin. Front. Cell Dev. Biol. 8:824. doi: $10.3389 /$ fcell.2020.00824

Yu, S., Zhou, C., Cao, S., He, J., Cai, B., Wu, K., et al. (2020). BMP4 resets mouse epiblast stem cells to naive pluripotency through ZBTB7A/B-mediated chromatin remodelling. Nat. Cell Biol. 22, 651-662. doi: 10.1038/s41556-0200516-x

Zaminy, A., Kashani, I. R., Barbarestani, M., Hedayatpour, A., Mahmoudi, R., Vardasbi, S., et al. (2008). Effects of melatonin on the proliferation and differentiation of rat adipose-derived stem cells. Indian J. Plast. Surg. 41, 8-14. doi: 10.4103/0970-0358.41104

Zhang, B., He, L., Liu, Y., Zhang, J., Zeng, Q., Wang, S., et al. (2018). Prostaglandin $\mathrm{E}$ is required for BMP4-Induced mesoderm differentiation of human embryonic stem cells. Stem Cell Rep. 10, 905-919. doi: 10.1016/j.stemcr.2018.01.024

Zhang, C. Z., Sun, H. Z., Li, S. L., Sang, D., Zhang, C. H., Jin, L., et al. (2019a). Effects of photoperiod on nutrient digestibility, hair follicle activity and cashmere quality in Inner Mongolia white cashmere goats. Asian-Australas J. Anim. Sci. 32, 541-547. doi: 10.5713/ajas.18.0154

Zhang, C. Z., Sun, H. Z., Zhang, C. H., Jin, L., and Li, S. L. (2019b). Effects of photoperiod on circadian clock genes in skin contribute to the regulation of hair follicle cycling of Inner Mongolia white cashmere goats. Anim. Sci. J. 91:e13320. doi: $10.1111 /$ asj. 13320

Zhang, C. Z., Sun, H. Z., Sheng, L. I., Sang, D., Zhang, C. H., and Jin, L. (2016). The Role of the circadian clock system in animal nutrition and metabolism. J. Domestic Anim. Ecol. 37, 1-8.

Zhang, J., Fei, T., Li, Z., Zhu, G., Wang, L., and Chen, Y. G. (2013). BMP induces cochlin expression to facilitate self-renewal and suppress neural differentiation of mouse embryonic stem cells. J. Biol. Chem. 288, 8053-8060. doi: 10.1074/jbc. M112.433995

Zhang, Y., Yu, J., Shi, C., Wang, Y., Yang, J., and Yang, T. (2013). Regulatory effect of $\beta$-catenin on proliferation of hair follicle stem cells involves pi3k/akt pathway. J. Appl. Biomed. 11, 131-141. doi: 10.2478/v10136-012-0019-6

Zhang, Q. L., Li, J. P., Chen, Y., Chang, Q., Li, Y. M., Yao, J. Y., et al. (2014). Growth and viability of liaoning cashmere goat hair follicles during the annual hair follicle cycle. Genet. Mol. Res. 13, 4433-4443. doi: 10.4238/2014.June.16.2

Zhang, Y., Tomann, P., Andl, T., Gallant, N. M., Huelsken, J., Jerchow, B., et al. (2009). Reciprocal requirements for EDA/EDAR/NF- $\kappa B$ and Wnt/B-Catenin signaling pathways in hair follicle induction. Dev. Cell 17, 49-61. doi: 10.1016/ j.devcel.2009.05.011

Conflict of Interest: The authors declare that the research was conducted in the absence of any commercial or financial relationships that could be construed as a potential conflict of interest.

Copyright $\odot 2021$ Zhang, Wang, Zhang, Wang, Ge and Wang. This is an open-access article distributed under the terms of the Creative Commons Attribution License (CC BY). The use, distribution or reproduction in other forums is permitted, provided the original author(s) and the copyright owner(s) are credited and that the original publication in this journal is cited, in accordance with accepted academic practice. No use, distribution or reproduction is permitted which does not comply with these terms. 